\title{
New Nuclear Power Technology Research Progress in China and Abroad Mingqi Wu
}

\author{
North China Electric Power University, Baoding, 071003, China \\ 15932177859@163.com
}

Keywords: Application of nuclear energy; Nuclear energy research

\begin{abstract}
Nuclear power is a clean, safe and mature technology, strong supply capacity, to large-scale application way of generating international technology development leveled off in 2015, the Chinese reactors construction accounted for $40 \%$ of the world. International nuclear energy application of the third generation of nuclear power units continue to improve, at present, in all kinds of fourth-generation nuclear power systems research, China's fourth generation nuclear power in air cooled fast reactor (GFR) and lead cooled fast reactor (LFR) into the reactor construction stage, China's nuclear power development in the spring.
\end{abstract}

\section{The Preface-world Nuclear Power Development Characteristics}

According to the independent energy and environmental policy experts Mycle Schneider and other cooperation wrote "the world nuclear industry status report 2015", by the mid - 2015, 30 countries operating nuclear power plants, there is only one than in previous years (Japan).[1] Nuclear power plant to produce 2.41 trillion KWH of surfing the Internet, compared with 2013 growth of $2.2 \%$, but still $9.4 \%$ lower than the peak in 2006. A total of 31 countries around the world are running nuclear reactors, nuclear reactor with a total of 391 seats, launched in 2014, compared to the same five reactors, closed 2 reactors, with a total installed capacity of 337 gigawatts $(\mathrm{GW})$, political influence by fukushima, Japan has not been running nuclear power unit. [2]Construction units, as of July 2015, including 14 countries 62 reactors under construction capacity reached 59 gigawatts (GW), $40 \%$ of the new project is located in China.

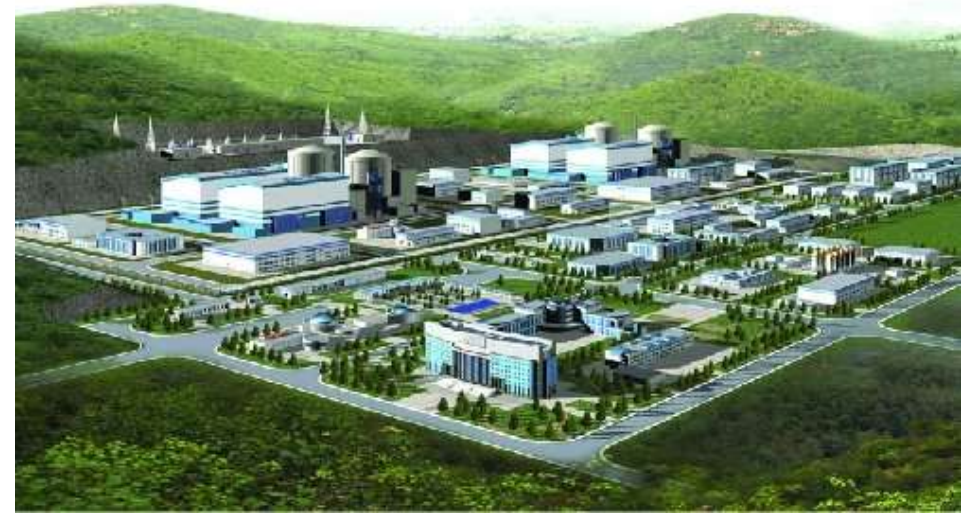

Figure 1. Finite Nuclear Power Plant

In the past three years the global nuclear power share remained stable, global share of $10.8 \%$ in 2014 , down from the peak of $17.6 \%$ in 1996. Nuclear power of global commercial energy $4.4 \%$ at a time. As with the previous year, the five largest nuclear countries are the United States, France, Russia, South Korea and China, in 2014, nuclear power generating capacity of the five countries account for $69 \%$ of global nuclear power generation, the American and French nuclear power accounted for half of the global nuclear power. [3] 


\section{All Kinds of New Nuclear Power Technology Research and Development}

The large scale development of nuclear power as efficient clean energy will play a great role in the sustainable development strategy in our country. At present, nuclear power plant in service mainly adopts generation, second generation and the second generation advanced pressurized water reactor technology, as the third generation of nuclear power system into the construction phase, the fourth generation advanced nuclear energy systems research has gradually become the world's nuclear power research hot spot.

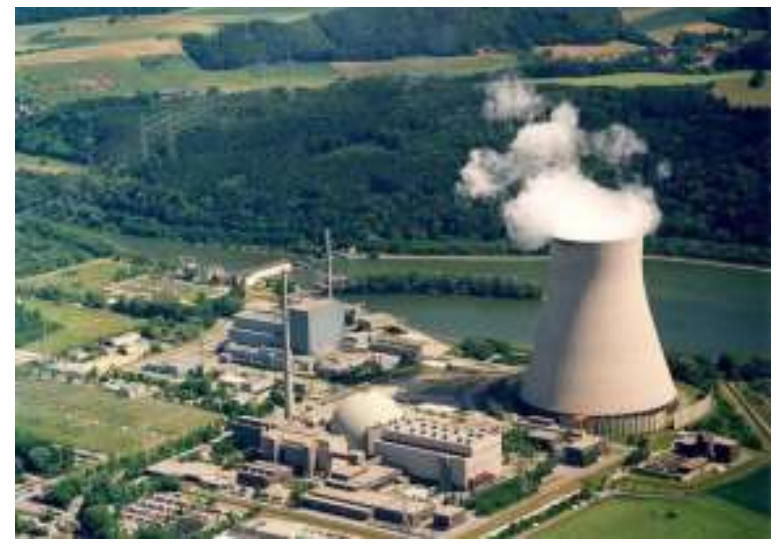

Figure 2. Finite Nuclear Power Plant Vision

The Development of the Third Generation of Nuclear Power Technology. Safety and economic behavior of the third generation reactor will be significantly better than that of the second generation reactor.[4]This includes the advanced nuclear fuel management technology, higher thermal efficiency, passive nuclear safety system, standardized design, thus reducing maintenance and investment costs.

AP1000 \& CAP1000. Short for AP1000 is Advanced Passive PWRS, 1000 level for its power, the DuiXing for Westinghouse electric company in accordance with the concept of Passive nuclear safety and design and sales of the third generation reaction DuiXing nuclear power plants. Its design is from the U.S. nuclear regulatory commission (NRC) received approval by the final design of the first third generation reactor. AP1000 also will be the mainstream of future reactor in mainland China.

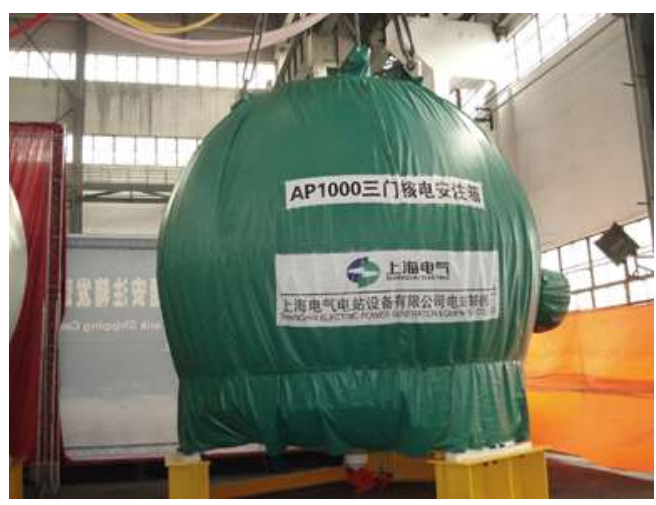

Figure 3. Finite AP1000

Its main features are: the adoption of active safety systems, safety related systems and parts cuts, competitive power generation costs, 60 years of design life, digital instrument control room, high, easy to build capacity factor (factory and site built a simultaneous), its design and performance characteristics to meet the requirements of the user requirements document (URD).

The world's first AP1000 nuclear power units for sanmen nuclear power plant unit, number one in self-independence of AP1000 China depends on the project, for the first time applied to the screening of large commercial nuclear power units in the main pump once face greater challenges in the development process, becomes the key issue in the project construction period delay, 
manufacturing quality control problem, first the subcontractor with the EMD to subcontractors making further strict quality control is resolved.[6,7] Followed by extreme ambient conditions of water loss test, thermal transient impact resistance ability find bearing parts need to be strengthened. Since then, Westinghouse, the EMD to carry out the second engineering and durability test, thrust tile CARDS appeared in the process of a local fatigue fracture. [5]Comprehensive review on October 29, 2015, AP1000 main pump performance meet the design requirements of technical specification. [2] on January 28, 2016, reactor coolant pump in sanmen nuclear power installation is complete, the site of the project success marks the AP1000 three generations of nuclear main pump installed successfully solved the technical problems, has cleared the obstacles for the three unit 1 power smoothly, on subsequent AP1000 landmark unit construction, its experience will be a good feedback to the China to a new independent brand CAP1400.[8] Inland nuclear power restart may be a step closer. Haiyang nuclear power plant during the same period for each of the first phase 2 $\mathrm{x} 1250 \mathrm{mw}$ reactors under construction.

ACP1000 "Hualong Number One". ACP1000 is "advanced PWR 1000 MW in China". By the China national nuclear corporation research and development, with independent intellectual property rights.[9]

ACP1000 is nuclear group in 30 years of experience in nuclear power design, construction, based on the digestion and absorption countries the introduction of the three generations of nuclear power technology, after more than ten years of continuous research and development, continuous improvement and independent innovation, give full consideration to the fukushima accident after the latest experience feedback, make full use of the achievements of domestic and foreign counterparts advantage resources and capabilities. Fuqing unit 5, and 6 , phase ii of fangcheng port, as well as multiple export unit is being built.[10]

\section{Reference}

[1] X.H.Zhang and Y.An.Lei. Translation of the 2015 World Nuclear Industry Status Report Summary 16/3/16.

[2] China National Nuclear Corporation the World's First AP1000 Unit First Complete 16/02/04 Main Pump Installed.

[3] 15/11/8 ACP1000 Wikipedia Page.

[4] Q.Q Ye. China's Nuclear Power Development Strategy Research[J]. 2010, 26(1):3-8.

[5] J.Q.Jing and H.W.Luan. The World's Nuclear Power Development and China's Nuclear Power Development [J]. Northeast Electric Power Technology, 2008, 29(2):48-52.

[6] T.Zhou, D.G.Lu and Y.R.Li. Nuclear Safety Culture and China's Nuclear Power Development [J]. Modern Electric Power, 2006, 23(5):16-23.

[7] S.L.Zou, B.Liu, J.H.Chen. The Present Situation and Prospect of China's Nuclear Power Development [J]. Journal of south China university (social science edition), 2004, 5(4):36-40.

[8] Y.P.Wang, S.F.Zhao and Y.J.Yuan. China's Nuclear Power Development Strategy Research in 2020[J]. China Nuclear Science and Technology Report, 2005(1):154-163.

[9] Z.X.Zhang. Outline of Nuclear Power Development in China[J]. Electric Power Construction , 2004, 25(2):1-4.

[10]L.F.Zhou. China's Nuclear Power Development is Analysed [J]. Economic Research Guide, 2011(7):200-201. 